\title{
Ureteric Anastomotic Leak, CTCAE
}

National Cancer Institute

\section{Source}

National Cancer Institute. Ureteric Anastomotic Leak, CTCAE. NCI Thesaurus. Code C143897.

A finding of leakage due to breakdown of a ureteral anastomosis (surgical connection of two separate anatomic structures). 